\title{
Predictors of psychosocial outcome of bipolar disorder: data from the Stanley Foundation Bipolar Network
}

\author{
Francis Bennett ${ }^{1}$, Sophie Hodgetts ${ }^{2}$, Andrew Close ${ }^{1}$, Mark Frye ${ }^{3}$, Heinz Grunze ${ }^{4}$, Paul Keck ${ }^{5,6}$, Ralph Kupka7, \\ Susan McElroy ${ }^{7}$, Willem Nolen ${ }^{8}$, Robert Post ${ }^{9}$, Lars Schärer ${ }^{10}$, Trisha Suppes ${ }^{11}$ and Aditya N. Sharma ${ }^{1,12,13^{*}}$ (D)
}

\begin{abstract}
Background: Impairments in psychosocial functioning have been demonstrated in 30-60\% of adults with bipolar disorder (BD). However, the majority of studies investigating the effect of comorbid mental health disorders and age at onset outcomes in BD have focused on traditional outcome measures such as mood symptoms, mortality and treatment response. Therefore, this project aimed to investigate the impact of comorbid mental health disorders and age at onset on longitudinal psychosocial outcome in participants with BD.

Method: Mixed effects modelling was conducted using data from the Stanley Foundation Bipolar Network. Baseline factors were entered into a model, with Global Assessment of Functioning (GAF) score as the longitudinal outcome measure. Relative model fits were calculated using Akaike's Information Criterion.

Results: No individual comorbidities predicted lower GAF scores, however an interaction effect was demonstrated between attention deficit hyperactivity disorder (ADHD) and any anxiety disorder $(t=2.180, p=0.030)$. Participants with $\mathrm{BD}$ I vs BD II ( $t=2.023, p=0.044)$ and those in the lowest vs. highest income class $(t=2.266, p=0.024)$ predicted lower GAF scores. Age at onset $(t=1.672, p=0.095)$ did not significantly predict GAF scores.

Conclusions: This is the first study to demonstrate the negative psychosocial effects of comorbid anxiety disorders and $\mathrm{ADHD}$ in $\mathrm{BD}$. This study adds to the growing database suggesting that comorbid mental health disorders are a significant factor hindering psychosocial recovery.
\end{abstract}

Keywords: Bipolar disorder, Social functioning, Comorbidity

\section{Background}

Bipolar disorder (BD) is a mood disorder characterised by recurrent episodes of mania, hypomania, and depression, separated by periods of euthymia. Although not characterised by mood symptoms, psychosocial functioning appears to remain impaired during euthymia (Marangell et al. 2009). Psychosocial functioning is an essential component of a person's quality of life (QoL), and includes social, psychological and occupational domains. In 2001, a landmark review found that between 30 and $60 \%$ of

\footnotetext{
*Correspondence: aditya.sharma@ncl.ac.uk

${ }^{13}$ Academic Psychiatry, Wolfson Research Centre, Campus for Ageing and Vitality, Newcastle University, Newcastle upon Tyne NE4 5PL, UK Full list of author information is available at the end of the article
}

adults with BD had significant impairments in occupational and social functioning during periods of euthymia (MacQueen et al. 2001). A possible explanation for pervasive psychosocial dysfunction may be the illness itself or the high prevalence of comorbid mental disorders in BD (Post et al. 2015). However, research into BD has often overlooked the role of psychosocial functioning.

High rates of anxiety disorders (AnxD) comorbid with $\mathrm{BD}$ have been found consistently in both epidemiological (Merikangas et al. 2011) and clinical (Otto et al. 2006) samples. A recent review of 25 studies concluded that the lifetime risk of developing a comorbid AnxD was 46.8\%, although epidemiological samples put this figure closer to $70 \%$ (Vazquez et al. 2014). Comorbid AnxD in subjects with $\mathrm{BD}$ are associated with a more severe illness 
course, including increased number of mood episodes, suicide attempts and hospitalizations, compared to BD alone (Merikangas et al. 2007). Despite this considerable evidence base, a recent review highlighted the current stagnation in AnxD comorbidity research, epitomised by the poor understanding of psychosocial factors, scarcity of treatment studies, and the lack of evidence base on antidepressants treating bipolar depression (Provencher et al. 2012). Although studies have shown associations between comorbid AnxD and poor psychosocial functioning (Scott et al. 2014), the picture is still far from clear.

Comorbid substance use disorders (SUD) are also prevalent the $\mathrm{BD}$ population, with epidemiological surveys putting lifetime prevalence of comorbid SUD at as high as $42.3 \%$ (Merikangas et al. 2007). However, with the exception of alcohol (Hobbs et al. 2011), the functional impacts and treatment options for individual SUD in BD have yet to be rigorously investigated.

Attention deficit hyperactivity disorder (ADHD) is a neurodevelopmental disorder, and its prevalence in $B D$ varies widely with the age at which it is estimated. Approximately $20 \%$ of adult patients with ADHD also have bipolar disorder, while $10-20 \%$ of patients with bipolar disorder have adult ADHD (Brus et al. 2014). As with SUD and AnxD, ADHD comorbidity has been associated with increased number of mood episodes, higher rates of suicide attempts (McIntyre et al. 2010) and psychosocial dysfunction (Sentissi et al. 2008).

Mental health comorbidities in BD are more likely to be multiple than singular, with the World Mental Health Survey reporting a $62 \%$ lifetime prevalence of 3 or more comorbidities when strict Diagnostic and Statistical Manual of Mental Disorders-IV (DSM-IV) criteria were applied (Merikangas et al. 2011). However, research into the psychosocial effects of multiple comorbidities in BD is limited, often due to lack of power in subgroup analyses (Sentissi et al. 2008). Although there is clear evidence of increased rates of both individual and multiple comorbidities in BD, their impacts on day-to-day functioning of people with $\mathrm{BD}$ have yet to be established.

Earlier age at onset (AAO) of BD is consistently linked with poorer clinical outcomes, including rapid cycling, greater number of mood episodes and increased risk of suicide (Leverich et al. 2007). Some studies have linked psychosocial dysfunction with younger ( $<18$ years) AAO (Perlis et al. 2009), although this finding is not consistent (Martinez-Aran et al. 2007). The studies that have focused on younger AAO suggest that psychosocial impairment is due to earlier disruption in the development of interpersonal skills needed to build and maintain healthy relationships as patients grow older (Levy and Manove 2012). However, while younger AAO is associated with an adverse course of illness in adulthood (Leverich et al. 2007), how these may be related to psychosocial functioning has received little attention (Perlis et al. 2009).

In this post hoc analysis we used data from an established database (Stanley Foundation Bipolar Network) (Post et al. 2001) to estimate the effects of comorbid mental health disorders and AAO on psychosocial outcomes in participants with BD. A novel aspect to this study is the use of statistical modelling techniques, specifically mixed effects modelling (MEM). Modelling has been used extensively in the behavioural sciences (Gerhard et al. 1995), while recognition of its utility in medical fields is growing. The STEP-BD group used MEM in two papers assessing psychosocial outcome measures (Otto et al. 2006; Perlis et al. 2009). Complex data sets, such as the SFBN, often violate the assumptions of general linear modelling; in particular, statistical assumptions relating to independence between observations are violated. In contrast, mixed effects modelling is particularly suited to data sets involving measurements obtained from individual patients that share socioeconomic, demographic or biomedical characteristics. Therefore, a key advantage of MEM is that it calculates how much of the variance in the sample is explained by each factor and, crucially, what residual variance is left. Most clinical studies lack sufficient numbers to run the more complex models, but the longitudinal nature and size of the SFBN cohort makes this a unique opportunity in psychiatric research.

\section{Aims of the study}

Psychosocial functioning is key to understanding the overall impact mental health disorders can have on an individual. In BD research, comorbid mental health disorders and age at onset have both been extensively investigated with traditional outcome measures such as mood symptoms, mortality and treatment response. In this study, we used Mixed-Effects Modelling on data collected by the Stanley Foundation Bipolar Network. The study aimed to demonstrate the effect of comorbid mental health disorders and age of onset on psychosocial functioning in participants with BD.

\section{Methods}

\section{Baseline assessments}

Information on comorbid mental health disorders and AAO was collected utilizing items from Structured Clinical Interview for DSM-IV-Patient (SCID-P) and Patient Questionnaire (PQ). AAO was defined as age at first hypomanic, manic, or depressive symptoms that were associated with functional impairment. AAO for BD was collected from the SCID-P, which a previous SFBN paper 
showed to be highly correlated with self-report from PQ $(r=0.80)$ (Leverich et al. 2007).

\section{Longitudinal outcome}

The Global Assessment of Functioning (GAF) is a wellvalidated instrument, which constitutes Axis V of DSMIV. It has been used extensively in $\mathrm{BD}$ research and has good inter-rater reliability (Jones et al. 1995). A criticism of the GAF is that it confounds mood and functioning by including mood symptoms in the scale descriptions. In the SFBN this was addressed by ensuring clinicians only used the GAF to rate functioning. Following an interview, clinicians rated the participant's global functioning on a scale of $0-100$. Three scores were recorded: best, worst (since last visit) and current. This study only included current score in order not to introduce a selection bias.

\section{Data selection}

The total sample study size in the original data was $\mathrm{n}=648$, with 21,993 GAF records. Only participants with complete data were included (see Fig. 1) which left a final sample size of $\mathrm{n}=469$, with 12,556 GAF records.

\section{Data analysis}

Mixed-effects models (MEMs) were developed using the strategy described by Pinheiro et al. (2017) to examine variation in psychosocial dysfunction among participants at follow-up. A GAF score for each participant was obtained at baseline and at follow-up. We implemented the methodology proposed by Vickers and Altman (2001) and used GAF at baseline in order to control for differences in the mean psychosocial function between sites in Europe (Netherlands and Germany) and USA. The impact of BD subtype of each participant, AAO and the mental health comorbidities on psychosocial outcome were also determined. The influences of demographic characteristics of participants were assessed by including sex and income as independent explanatory variables. Independent explanatory variables were assessed within models additively. The potential impact of multiple interactions between AnxD, SUD and ADHD on psychosocial outcome was also explored. Individuals were grouped according to their respective locations (Europe or USA). Study location was then specified as a random-effect within the model in order to capture potential sources of unmeasured variation in psychosocial outcome. In addition, GAF at baseline within the random-effects structure was incorporated to generate a random intercept and random slope model that controlled for variation in overall mean and gradient between locations. Multi-model inference (Burnham and Anderson 2002) was used to compare models with additive terms to those models that incorporated both additive and interaction actions terms.

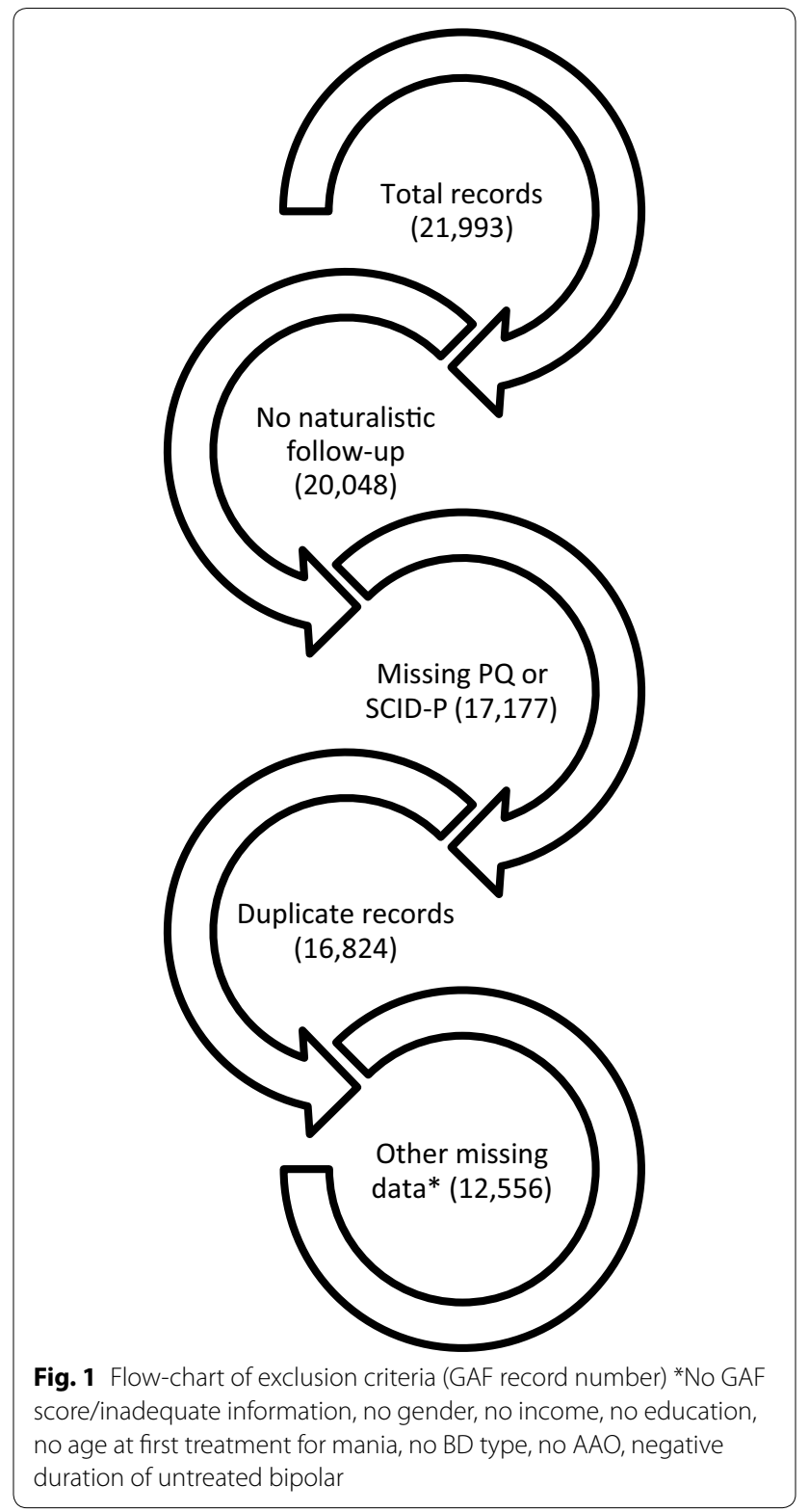

A model with the lowest Akaike's Information Criterion (AIC) (Akaike 1973) was considered to be the model that best described variation within data.

\section{Results}

\section{Preliminary analysis}

There were greater numbers of participants included in the final analysis from USA $(n=332)$ than from Europe $(\mathrm{n}=137)$. However, a Chi-squared test of independence did not find differences in the distribution of genders between USA (female:male, 189:124) and Europe (female:male, 70:63) $\left(X_{2}=2.17, p=0.141\right)$. In contrast, the distribution of mental health comorbidities, namely 
AnxD $\left(X_{2}=22.98, p=<0.001\right)$, ADHD $\left(X_{2}=8.23\right.$, $p=0.004)$ and SUD $\left(X_{2}=20.29, p<0.001\right)$ all differed significantly between locations, and were higher in the US than in Europe. No significant differences in the distribution of BD subtypes $\left(X_{2}=0.44, p=0.081\right)$, or income classes $\left(X_{2}=0.58, p=0.748\right)$ was observed

Table 1 Demographic characteristics and comorbidity in USA vs Europe

\begin{tabular}{|c|c|c|c|c|c|}
\hline & $\begin{array}{l}\text { USA } \\
(n=332, \\
70.8 \%)\end{array}$ & $\begin{array}{l}\text { Europe } \\
(n=137 \\
29.2 \%)\end{array}$ & $\begin{array}{l}\text { Total } \\
(n=469, \\
100 \%)\end{array}$ & $x^{2}$ & $p$-value \\
\hline \multicolumn{6}{|l|}{ Gender } \\
\hline Female & 59.9 & 52.6 & 57.8 & & \\
\hline Male & 40.1 & 47.4 & 42.2 & 2.17 & 0.141 \\
\hline \multicolumn{6}{|l|}{ Income (\$) } \\
\hline$<20,000$ & 38.9 & 36.5 & 38.2 & & \\
\hline $20,000-59,999$ & 38.6 & 42.3 & 39.7 & & \\
\hline$>60,000$ & 22.6 & 21.2 & 22.2 & 0.58 & 0.748 \\
\hline \multicolumn{6}{|l|}{ BD type } \\
\hline BDI & 84.3 & 83.2 & 84.0 & & \\
\hline $\mathrm{BD} \|$ & 13.6 & 15.3 & 14.1 & & \\
\hline $\begin{array}{c}\text { BD cyclo- } \\
\text { thymic }\end{array}$ & 2.1 & 1.5 & 1.9 & 0.44 & 0.081 \\
\hline \multicolumn{6}{|l|}{ Comorbidity } \\
\hline$A n \times D$ & 52.7 & 28.5 & 45.6 & 22.98 & $<0.001$ \\
\hline Panic disorder & 35.8 & 19.7 & 31.1 & & \\
\hline Chronic AnxD & 33.4 & 16.8 & 28.6 & & \\
\hline$O C D$ & 22.9 & 4.4 & 17.5 & & \\
\hline ADHD & 16.6 & 6.6 & 13.6 & 8.23 & 0.004 \\
\hline SUD & 47.3 & 24.8 & 40.5 & 20.29 & $<0.001$ \\
\hline$A n \times D+S U D$ & 26.2 & 9.5 & 19.2 & & \\
\hline ADHD+SUD & 9.9 & 2.9 & 7.9 & & \\
\hline $\mathrm{ADHD}+\mathrm{AnxD}$ & 13.3 & 5.8 & 11.1 & & \\
\hline
\end{tabular}

between USA and Europe. Demographic information for the whole sample is given in Table 1, while clinical and GAF summaries are given in Table 2.

Preliminary analysis undertaken using a Wilcoxon Signed-Rank Test indicated that the location of mean of GAF measured at baseline was significantly different between locations ( $\mathrm{W}=23,472, p=0.0325)$, and higher in Europe. The location of the mean GAF derived at follow-up was also found to be significantly different between locations ( $\mathrm{W}=24,844, p=0.0012$ ). It was not possible to explore the impact of educational attainment in the assessment of variation in GAF due to imbalance in sample size between the lower and higher levels of attainment. Similarly, participants with BD NOS were removed from further analyses due to insufficient sample size $(n=9)$. Subsequently, variation in psychosocial function among 446 participants was analysed.

\section{Statistical analysis of global assessment of functioning (GAF)}

The relative fits of MEMs were compared using multimodel inference. A model was considered a plausible fit to data if the difference in AIC between models did not exceed $\Delta_{\mathrm{I}}<2$ (Table 3 ). The model incorporating an interaction between AnxD and ADHD was considered to be the best candidate model from the specific set of models compared (AIC $=3582.256, \Delta_{\mathrm{I}}=0.000$ ) (Table 3). The model incorporating comorbidities additively was ranked second within the model set $\left(\mathrm{AIC}=3588.113, \Delta_{\mathrm{I}}=5.361\right)$ and models that examined interactions between ADHD and SUD (AIC $\left.=3593.008, \Delta_{\mathrm{I}}=10.256\right)$ and Anxiety Disorders and SUD $\left(\mathrm{AIC}=3594.422, \Delta_{\mathrm{I}}=11.670\right)$ were ranked third and fourth, respectively.

Results generated by MEMs examining variation in GAF scores at follow-up, and incorporating an interaction between AnxD and ADHD are presented in Table 4.

Table 2 Sample demographics, mean GAF at baseline, and follow-up by location, sex and BD subtype

\begin{tabular}{|c|c|c|c|c|c|c|}
\hline Location & Sex & $\begin{array}{l}\text { DSM-IV bipolar } \\
\text { disorder subtype }\end{array}$ & $\begin{array}{l}\text { Mean follow-up } \\
\text { attendance (\%) }\end{array}$ & $\begin{array}{l}\text { Mean GAF } \\
\text { baseline }\end{array}$ & $\begin{array}{l}\text { Mean GAF } \\
\text { follow-up }\end{array}$ & Sample size (\%) \\
\hline Europe & Female & BD I & 30.53 & 63.75 & 66.68 & $57(12.5)$ \\
\hline Europe & Female & $\mathrm{BD} \|$ & 40.85 & 73.08 & 71.62 & $13(2.9)$ \\
\hline Europe & Female & BD NOS & 41.00 & 70.00 & 32.50 & $2(0.40)$ \\
\hline Europe & Male & $\mathrm{BD} \mid$ & 31.04 & 64.16 & 71.02 & $56(12.3)$ \\
\hline Europe & Male & $\mathrm{BD} \|$ & 38.86 & 67.57 & 80 & $7(1.5)$ \\
\hline Europe & Male & BD NOS & NA & NA & NA & NA \\
\hline USA & Female & $\mathrm{BD} \mid$ & 24.22 & 62.84 & 65.25 & $165(36.3)$ \\
\hline USA & Female & BD ॥ & 24.08 & 64.33 & 68.46 & $24(5.3)$ \\
\hline USA & Female & BD NOS & 11.75 & 54.00 & 62.75 & $4(0.9)$ \\
\hline USA & Male & BDI & 28.47 & 61.02 & 65.03 & $104(22.9)$ \\
\hline USA & Male & $\mathrm{BD} \|$ & 26.50 & 63.20 & 67.70 & $20(4.4)$ \\
\hline USA & Male & BD NOS & 42.33 & 71.00 & 61.00 & $3(0.7)$ \\
\hline
\end{tabular}


Table 3 Multi-model inference indicating that the model incorporating two interactions terms best describes the data

\begin{tabular}{|c|c|c|c|c|c|}
\hline Fixed effects structure (comorbidities) & $d f$ & Log likelihood & AIC & $\Delta_{\mathrm{i}}$ & wt \\
\hline Anxiety disorders and ADHD & 24 & -1762.376 & 3582.752 & 0.000 & 0.928 \\
\hline Additive terms & 25 & -1769.056 & 3588.113 & 5.361 & 0.064 \\
\hline ADHD and substance use disorder & 23 & -1773.504 & 3593.008 & 10.256 & 0.006 \\
\hline Anxiety disorder and substance use disorder & 27 & -1770.211 & 3594.422 & 11.670 & 0.003 \\
\hline
\end{tabular}

Table 4 Mean GAF score at follow-up (intercept) and change with respect to explanatory variables

\begin{tabular}{|c|c|c|c|c|c|c|}
\hline Parameter & Estimate & $95 \% \mathrm{Cl}$ & se & $d f$ & $t$-value & $p$-value \\
\hline Intercept & 67.757 & $62.225,73.518$ & 2.662 & 431 & 25.456 & $\leq 0.000$ \\
\hline BD: subtype-2 & 3.191 & $0.146,0.645$ & 1.578 & 431 & 2.023 & 0.044 \\
\hline Clinical follow-up attendance & -0.008 & $0.407,6.908$ & 0.029 & 431 & -0.287 & 0.774 \\
\hline GAF baseline & 0.410 & $0.019,0.308$ & 0.114 & 431 & 3.586 & $\leq 0.000$ \\
\hline Age of onset & 0.120 & $-4.657,2.122$ & 0.072 & 431 & 1.672 & 0.095 \\
\hline Anxiety disorder & -2.162 & $-4.823,0.498$ & 1.354 & 431 & -1.597 & 0.111 \\
\hline ADHD & 1.279 & $-2.979,5.537$ & 2.166 & 431 & 0.591 & 0.555 \\
\hline Substance use disorder & 1.552 & $-0.869,3.973$ & 1.232 & 431 & 1.260 & 0.208 \\
\hline Sex: male & 0.771 & $-1.650,3.192$ & 1.232 & 431 & 0.626 & 0.532 \\
\hline Income-2 ${ }^{\mathrm{a}}$ & -0.551 & $-3.261,2.160$ & 1.379 & 431 & -0.399 & 0.690 \\
\hline Income- $3^{\mathrm{a}}$ & 3.572 & $0.474,6.670$ & 1.576 & 431 & 2.266 & 0.024 \\
\hline BD subtype-2: GAF baseline & -0.265 & $-0.518,-0.012$ & 0.129 & 431 & -2.059 & 0.040 \\
\hline BD subtype-2: age of onset & -0.244 & $-0.518,-0.029$ & 0.139 & 431 & -1.758 & 0.080 \\
\hline Anxiety disorder: ADHD & -6.953 & $-13.222,-0.683$ & 3.190 & 431 & -2.180 & 0.030 \\
\hline
\end{tabular}

a Income-2: 20,000-59,999 (USD), income-3: > 60,000 (USD)

The global mean (Intercept) GAF at follow-up for participants with BDI (reference level) was 67.757 and was significantly different from zero $(t=25.456, p \leq 0.000)$. Participants with BDII were found to have significantly higher GAF scores at follow-up in comparison to participants with BDI $(t=2.023, p=0.044)$. Baseline GAF for participants was found to be significantly and positively associated with GAF at follow-up $(t=3.586,=p \leq 0.000)$. In addition, a significant negative association was found for participants with BDII and psychosocial function at baseline $(t=-2.059180, p=0.017)$, suggesting lower psychosocial functioning in BDII patients at baseline. In contrast, there was no significant relationship between BD subtype and AAO and psychosocial function at follow-up. Individuals grouped within the highest income class were significantly associated with higher GAF at follow-up in comparison to participants in the lowest class $(t=2.266, p=0.024)$. In contrast, there was no significant difference at follow-up between participants within income class-1 and income class-2. Comorbidities included as additive terms within the model, AnxD, SUD and ADHD, did not significantly affect psychosocial function at follow-up. However, when AnxD and ADHD were incorporated as an interaction term, a significant negative effect on GAF at follow-up was observed $(t=2.180, p=0.030)$. The mean GAF at follow-up was not significantly affected by variation in duration of follow-up, and no significant differences were observed in GAF score at follow-up between females and males.

\section{Discussion}

The aim of this study was to investigate the impact of comorbid mental disorders and AAO on psychosocial functioning in an international sample of participants with $\mathrm{BD}$. These factors were entered into MEM with GAF score as the longitudinal psychosocial outcome measure. The principle finding is that $\mathrm{BD}$ comorbid with ADHD and AnxD predicted lower GAF scores, particularly in BDI. Due to the influence of confounding collinearity between explanatory variables, it was not possible to construct a single model that examined the multiplicative effects between all comorbidities simultaneously. Nevertheless, a set of MEMs were developed that first examined the effects of comorbidities additively, in addition to models that examined the multiplicative effects between comorbidities independently. Individual comorbidities were explored independently within the final model, with 
no single comorbidity reaching statistical significance in predicting psychosocial outcome.

The high rate of comorbid AnxD in BD (45.6\%) demonstrated in this study is a well-replicated finding (Simon et al. 2004). BD and comorbid AnxD alone did not predict poorer psychosocial function in the present study. This adds to a limited evidence base, and warrants further investigation. One explanation for this finding could be that the diagnostic criteria used did not capture the full spectrum of anxiety states and their effects.

As discussed earlier, rates of comorbid ADHD and BD vary widely according to age group. In the current study comorbid ADHD (13.6\%) was less prevalent than both AnxD (45.6\%) and SUD (40.5\%). Currently, only two previous papers have looked at psychosocial outcome in comorbid ADHD and BD (Sentissi et al. 2008; Wilens et al. 2003). A study using more specific social functioning measures (SF-36 Health Survey and Social Adjustment Scale) found that poorer scores were predicted by ADHD comorbidity (Sentissi et al. 2008). Another smaller study found only a trend towards poorer global psychosocial functioning (GAF) in the ADHD group (Wilens et al. 2003). Alongside the current results, this may suggest a specific social dysfunction related to ADHD comorbidity, since both studies also found that attention domains were significantly more impaired than hyperactivity domains in the comorbid ADHD group (Sentissi et al. 2008; Wilens et al. 2003). The evidence regarding specific attention deficits and social dysfunction needs further replication, however, it may be that the relationship between $\mathrm{ADHD}$ and $\mathrm{BD}$ depends upon to specific aspects of attention that are affected.

The current study did not find a predictive effect of comorbid SUD on psychosocial dysfunction in BD. It may have been an over-simplification to analyse all types of SUD together in this study. Alcohol and cannabis were the most widely abused substances in the SFBN sample, but a recent review highlighted the differential impacts of these two SUDs in BD (Cerullo and Strakowski 2007). The current results are especially interesting when looking at the new DSM-5 (American Psychiatric Association 2013) criteria for SUD, which no longer differentiate between substance abuse and dependence. Instead, SUD severity is classified by the number of criteria met. Of the 11 criteria listed three relate to social impairment, making it possible to have a SUD diagnosis without exhibiting any social dysfunction.

To the authors' knowledge, this is the first paper that examines the effect of comorbid ADHD and AnxD on psychosocial outcome in BD. A key similarity between comorbid ADHD and AnxD individually with $\mathrm{BD}$ is the persistence of their symptoms during periods of euthymia (Bernardi et al. 2010). This is likely to hinder psychosocial recovery between mood episodes, leading to reduced quality of life. The chronic nature of comorbid ADHD can lead to underreporting the functional impact of symptoms, (Sandra Kooij et al. 2008) although this has yet to be demonstrated in comorbid AnxD. We found that participants within the SFBN cohort with AnxD were significantly more likely to also have ADHD $(\mathrm{OR}=5.821,95 \% \mathrm{CI} 3.00-12.233)$. This suggests a heavy burden of ADHD in those participants with comorbid AnxD and BD. While the detrimental influence of such a potent combination of mental health disorders is perhaps not surprising, the underlying pathophysiological mechanisms merit further investigation.

The implications for treatment also merit discussion. There is very sparse guidance on treatment of comorbid mental health disorders in BD. The UK National Institute for Health and Care Excellence (NICE) guidelines merely state that clinicians should be "alert to the potential for drug interactions and use clinical judgement" (National Collaborating Centre for Mental Health 2014). American Psychiatric Association guidelines state treatment for comorbid AnxD and BD should "proceed concurrently" (American Psychiatric Association 2002). Canadian/ISBD guidelines state that when ADHD is comorbid with mood disorders then the condition causing most impairment should be treated first (Bond et al. 2012). This scenario can pose challenges for clinicians, as all three conditions are likely to be interacting to worsen the course of the other. In comorbid BD and ADHD, there is evidence in both children and adults to suggest a mood stabiliser and stimulant are effective in treating their respective symptoms (Findling et al. 2007). However, in adults there is also evidence of stimulant associated (hypo)mania (Wingo and Ghaemi 2008). On the other hand, one could also consider psychological treatment for the comorbid ADHD such as CBT or skills' training, which is not likely to harm treatment of $\mathrm{BD}$. The presence of an additional AnxD with ADHD and BD further complicates matters, as dual-action monoamine reuptake inhibitors also risk precipitating a (hypo)manic episode, although again this would not be the case for psychological treatments such as CBT (Goodwin et al. 2016).

Participants with BDII were significantly more likely on average to exhibit higher GAF scores at follow-up than participants with BDI. This is in line with previous findings showing higher GAF scores in BDII patients compared to BDI patients, despite similar illness duration, family history, previous suicide attempts, and overall psychiatric comorbidity (Dell'Osso et al. 2017b). This also indirectly supports the notion that psychotic symptoms that are particularly prevalent in BDI patients, may contribute to the lower GAF scores seen in this group (Dell'Osso et al. 2017a). This finding is also in line with 
the core criteria for mania as set out in DSM 5, that the mood episode impairs social or occupational functioning. AAO did not significantly influence the mean GAF at follow-up. As discussed previously, there is still sparse literature on the effects of earlier AAO on psychosocial functioning and their conclusions are varied (MartinezAran et al. 2007; Perlis et al. 2009). It is important to note that this study used age at first (hypo)manic symptoms or depressive symptoms with dysfunction to define AAO.

Participants in the highest income class were significantly more likely to yield better outcomes than those in the lowest income class. Numerous studies have shown that low socioeconomic status (SES) has significant detrimental impacts on mental health at a population level (Lorant et al. 2003). However, there is little evidence regarding the effects of SES on psychosocial functioning in BD. One study found no association between education levels and functional outcome (Schoeyen et al. 2011), although the outcome was 'disability pension'; a fairly crude measure of psychosocial functioning.

The confounding effect observed between explanatory variables may be an important reason as to why individual assessment of the effects of comorbidities appeared to be spurious. Nevertheless, when we assess the individual effects in conjunction with the interaction term we are able to ascertain the overall effect of mental health comorbidities on psychosocial outcomes. As our results indicate, those with multiple comorbidities (AnxD and ADHD) experience significantly reduced psychosocial function at follow-up.

The present study is not without limitation. First, while it is important that researchers use standardised scoring instruments in order to reduce bias and increase the replicability of their findings, the GAF has several limitations. Indeed, it has been suggested that it lacks the sensitivity to assess longitudinal change in an individual patient (Soderberg et al. 2005). Moreover, the GAF is global measure, and as such fails to capture the contributions of each specific dimension of psychosocial functioning to overall dysfunction. The GAF also specifically excludes functional impairment due to "physical or environmental limitations", yet it is difficult to see how raters can distinguish aetiologically between physical or environmental and psychosocial factors.

A second critical limitation to this study is that it did not control for mood state. The possible impact of mood state on the present findings is two-fold. Firstly, depressive symptoms, even more than manic, are strong predictors of poor psychosocial functioning (Morriss et al. 2013). However, in the present study, it is not possible to replicate this relationship. Secondly, it has been shown that the incidence rates of comorbidities are sensitive to mood state, when assessed cross-sectionally (Post et al. 2018) as in the present study. It is also important to note that this study did not include medical comorbidities. These certainly play a significant role in psychosocial dysfunction but were beyond the scope of the current paper.

A third critical limitation is that the comorbid conditions were characterised by the presence of a lifetime diagnosis, and whether patients continued to manifest these difficulties consistently over their lifetime is not known. This limitation would be of particular importance for ADHD, as a substantial group of patients may have the comorbidity in childhood and/or adolescence, but no longer in adulthood. Similarly, severity of each of the comorbid problems was not assessed. Any anxiety-specific disorder was considered for inclusion in the category, and how individual anxiety disorders or their combination may have affected the relationship to function cannot be determined in this study. In addition, while the incidence of comorbidities in this study population where similar to those reported in the literature, the fact that the population was drawn largely from academic tertiary care facilities may limit the generalizability of the results and conclusions to other populations.

It is also important to challenge some of the assumptions that may be drawn from this paper, including the idea of a unidirectional relationship between the significant predictors and psychosocial dysfunction. As this study was conducted in adults, with data on predictors collected retrospectively, the relationships inferred are not conclusive. Future work should aim to clarify these findings using prospective studies starting in childhood to determine differences between those who do and do not go on to develop BD. This will help to inform the development of interventions aimed specifically at psychosocial dysfunction.

\section{Conclusion}

In summary, this project has demonstrated the negative impact of comorbid AnxD and ADHD on psychosocial functioning in BD. Both inpatient and population studies have demonstrated the alarmingly high prevalence of comorbid disorders in $\mathrm{BD}$, however current guidelines offer little help to clinicians when managing these disorders. Our findings suggest a unique interaction between AnxD and ADHD in BD, which will need further research to both replicate and explore this relationship and ascertain optimal therapeutic interventions. Resolution of clinical symptoms in BD is rarely followed by recovery of psychosocial functioning, and this study has added insights into the role of AnxD and ADHD comorbid disorders in impairing global psychosocial functioning. 


\section{Acknowledgements}

This study was supported by the Stanley Medical Research Institute. We also acknowledge the very substantial contributions of both Gabriele S. Leverich, MSW and the late Lori Altshuler, MD.

\section{Authors' contributions}

$\mathrm{FB}, \mathrm{SH}$ and AS developed the study hypothesis and concept of the paper, $A C$ conducted the primary data analysis. Raw data were collected by $H G, L S$, PK, SME, RP, MF, RK, WN and TS. FB and SH equally contributed to drafting the article which has been edited by AS, AC, HG and RP. All authors read and approved the final manuscript.

\section{Funding}

The original research was supported by the Stanley Medical Research Institute. The supporters had no role in the design, analysis, interpretation, or publication of this study. Funding for this project was received from the North East branch of the Mental Health Foundation in United Kingdom to allow for development of a data dictionary. The grant award did not influence study methodology, aims, data analysis or the manuscript. None of the authors have received payment to write this article by any pharmaceutical company or other agency.

\section{Availability of data and materials}

The datasets used and/or analysed during the current study are available from the corresponding author on reasonable request.

\section{Ethics approval and consent to participate}

All patients participating in the Stanley Foundation Bipolar Network provided written informed consent and volunteered for the naturalistic follow-up study in which clinical state and medications were prospectively assessed. Ethical approval was granted by the local ethics committees at each of the seven participating academic sites: NIMH Bethesda, the University Hospitals of Los Angeles, Dallas, Cincinnati (all USA), Utrecht (The Netherlands), Freiburg and Munich (both Germany).

\section{Consent for publication}

All authors contributed to and approved the final manuscript and gave their consent for publication.

\section{Competing interests}

Mark A. Frye has received grant support from AssureRx, Mayo Foundation, Myriad, National Institute of Alcohol Abuse and Alcoholism (NIAAA), National Institute of Mental Health (NIMH), Pfizer. He has served as a consultant (Mayo) to Janssen, Mitsubishi Tanabe Pharma Corporation, Myriad, Neuralstem Inc., Otsuka American Pharmaceutical, Sunovion, Teva Pharmaceuticals. His employer Mayo Clinic has a financial interest in AssureRX and the technology referenced in this publication/presentation.Heinz Grunze received grants/ research support, consulting fees and honoraria within the last 3 years from Gedeon Richter, Janssen-Cilag, Lundbeck, Otsuka, Pfizer and Servier.Dr. Keck has been reimbursed for consulting to Otsuka and Lyndra. He is a co- inventor on United States Patent No. 6387956: Shapira NA, Goldsmith TD, Keck, PE Jr. (University of Cincinnati) Methods of treating obsessive-compulsive spectrum disorder comprises the step of administering an effective amount of tramadol to an individual. Filed March 25, 1999; approved May 14, 2002. Dr. Keck has received no financial gain from this patent.Ralph Kupka has received speakers honoraria over the past 3 years from Lundbeck, Janssen, and Sanofi.W.A. Nolen has received grants from the Netherlands Organisation for Health Research and Development, the European Union; has received honoraria/speaker's fees from Lundbeck and Aristo Pharma, and has served as consultant for Daleco Pharma.Susan McElroy is a consultant to or member of the scientific advisory boards of Bracket, F. Hoffmann-La Roche Ltd., MedAvante, Mitsubishi Tanabe Pharma America, Myriad, Novo Nordisk, Shire, and Sunovion. She is a principal or co-investigator on studies sponsored by the Allergan, Brainsway, Marriott Foundation, Myriad, National Institute of Mental Health, Novo Nordisk, Shire, and Sunovion. She is also an inventor on United States Patent No. 6,323,236 B2, Use of Sulfamate Derivatives for Treating Impulse Control Disorders, and along with the patent's assignee, University of Cincinnati, Cincinnati, Ohio, has received payments from Johnson \& Johnson, which has exclusive rights under the patent.Robert Post has received speaker's honoraria over the past 3 years from AstraZeneca, Validus, Sunovion, Takeda, Pamlabs.Lars Schärer received grants/research support from WHO, BMZ, OCHA, WFP, UNICEF, European
Commission, IBM, TigerLogic, Omnis.Trisha Suppes in the past 36 months has reported grants from National Institute of Mental Health, Sunovion Pharamaceuticals, Elan Pharma International Limited, VA Cooperative Studies Program, Pathway Genomics, Stanley Medical Research Institute, National Institute of Health, Palo Alto Health Sciences, and National Institute on Drug Abuse; consulting fees from A/S H. Lundbeck, Sunovion, and Merck \& Co; honoraria from Medscape Education, Global Medical Education, and CMEology; royalties from Jones and Bartlett and UpToDate; and travel reimbursement from A/S H. Lundbeck, Sunovion Pharmaceuticals, Inc., Global Medication Education, CMEology, and Merck \& Co.Aditya Sharma has received research grants from the National Institute for Health Research (UK) and speaker honoraria from the British Association for Psychopharmacology.Sophie Hodgetts, Francis Bennett and Andrew Close declares no competing interests.

\section{Author details}

${ }^{1}$ Institute of Neuroscience, Newcastle University, Newcastle upon Tyne, UK. ${ }^{2}$ School of Psychology, University of Sunderland, Sunderland, UK. ${ }^{3}$ Department of Psychiatry \& Psychology, Mayo Clinic, Rochester, MN, USA. ${ }^{4}$ PMU Nuremberg \& Psychiatrie Schwäbisch Hall, Schwäbisch Hall, Germany. ${ }^{5}$ Linder Center of Hope, Mason, OH, USA. ${ }^{6}$ Biological Psychiatry Program, University of Cincinnati Medical College, Cincinnati, OH, USA. ${ }^{7}$ Department of Psychiatry, VU University Medical Center, Amsterdam, The Netherlands. ${ }^{8}$ University of Groningen, University Medical Center Groningen, Groningen, The Netherlands. ${ }^{9}$ Bipolar Collaborative Network, Bethesda, MD, USA. ${ }^{10}$ Department of Psychiatry, and Psychotherapy Medical Center, University of Freiburg, Faculty of Medicine, Freiburg im Breisgau, Germany. ${ }^{11}$ School of Medicine and V.A. Palo Alto Health Care System Palo Alto, Stanford University, Palo Alto, CA, USA. ${ }^{12}$ Northumberland Tyne and Wear NHS Foundation Trust, Newcastle upon Tyne, UK. ${ }^{13}$ Academic Psychiatry, Wolfson Research Centre, Campus for Ageing and Vitality, Newcastle University, Newcastle upon Tyne NE4 5PL, UK

Received: 6 September 2019 Accepted: 5 November 2019

Published online: 16 December 2019

\section{References}

Akaike $\mathrm{H}$. Information theory and an extension of the maximum likelihood principle. In: Paper presented at the 2nd international symposium on information theory, Budapest, Akademiai Kiado; 1973.

American Psychiatric Association. Practice guideline for the treatment of patients with bipolar disorder (revision). Am J Psychiatry. 2002;159:1-50.

American Psychiatric Association. Diagnostic and statistical manual of mental disorders. 5th ed. Washington, DC: APA Press; 2013.

Bernardi S, Cortese S, Solanto M, Hollander E, Pallanti S. Bipolar disorder and comorbid attention deficit hyperactivity disorder. A distinct clinical phenotype? Clinical characteristics and temperamental traits. World J Biol Psychiatry. 2010;11:656-66.

Bond DJ, Hadjipavlou G, Lam RW, McIntyre RS, Beaulieu S, Schaffer A, et al. The Canadian network for mood and anxiety treatments (CANMAT) task force recommendations for the management of patients with mood disorders and comorbid attention-deficit/hyperactivity disorder. Ann Clin Psychiatry. 2012;24:23-37

Brus MJ, Solanto MV, Goldberg JF. ADHD vs. bipolar disorder in the DSM-5 era: a challenging differentiation for clinicians. J Psychiatr Pract. 2014;20:428-37.

Burnham KP, Anderson DR. Model selection and multimodel inference: a practical information-theoretic approach. New York: Springer Sci Bus Media; 2002

Cerullo MA, Strakowski SM. The prevalence and significance of substance use disorders in bipolar type I and II disorder. Subst Abuse Treat Prev Policy. 2007;2:29.

Dell'Osso B, Camuri G, Cremaschi L, Dobrea C, Buoli M, Ketter TA, et al. Lifetime presence of psychotic symptoms in bipolar disorder is associated with less favorable socio-demographic and certain clinical features. Compr Psychiatry. 2017a;76:169-76.

Dell'Osso B, Dobrea C, Cremaschi L, Buoli M, Miller S, Ketter TA, et al. Italian bipolar II vs I patients have better individual functioning, in spite of overall similar illness severity. CNS Spectr. 2017b;22:325-32. 
Findling RL, Short EJ, McNamara NK, Demeter CA, Stansbrey RJ, Gracious BL, et al. Methylphenidate in the treatment of children and adolescents with bipolar disorder and attention-deficit/hyperactivity disorder. J Am Acad Child Adolesc Psychiatry. 2007;46:1445-53.

Gerhard A, Clogg C, Sobel M. Handbook of statistical modeling for the social and behavioral sciences. New York: Springer; 1995.

Goodwin GM, Haddad PM, Ferrier IN, Aronson JK, Barnes T, Cipriani A, et al. Evidence-based guidelines for treating bipolar disorder: revised third edition recommendations from the British Association for Psychopharmacology. J Psychopharmacol. 2016;30:495-553.

Hobbs JDJ, Kushner MG, Lee SS, Reardon SM, Maurer EW. Meta-analysis of supplemental treatment for depressive and anxiety disorders in patients being treated for alcohol dependence. Am J Addict. 2011;20:319-29.

Jones SH, Thornicroft G, Coffey M, Dunn G. A brief mental health outcome scale-reliability and validity of the global assessment of functioning (GAF). Br J Psychiatry. 1995;166:654-9.

Leverich GS, Post RM, Keck PE Jr, Altshuler LL, Frye MA, Kupka RW, et al. The poor prognosis of childhood-onset bipolar disorder. J Pediatr. 2007;150:485-90.

Levy B, Manove E. Functional outcome in bipolar disorder: the big picture. Depress Res Treat. 2012;2012:12.

Lorant V, Deliege D, Eaton W, Robert A, Philippot P, Ansseau M. Socioeconomic inequalities in depression: a meta-analysis. Am J Epidemiol. 2003;157:98-112.

MacQueen GM, Young LT, Joffe RT. A review of psychosocial outcome in patients with bipolar disorder. Acta Psychiatr Scand. 2001;103:163-70.

Marangell LB, Dennehy EB, Miyahara S, Wisniewski SR, Bauer MS, Rapaport MH, et al. The functional impact of subsyndromal depressive symptoms in bipolar disorder: data from STEP-BD. J Affect Disord. 2009;114:58-67.

Martinez-Aran A, Vieta E, Torrent C, Sanchez-Moreno J, Goikolea JM, Salamero $\mathrm{M}$, et al. Functional outcome in bipolar disorder: the role of clinical and cognitive factors. Bipolar Disord. 2007;9:103-13.

Mclntyre RS, Kennedy SH, Soczynska JK, Nguyen HT, Bilkey TS, Woldeyohannes $\mathrm{HO}$, et al. Attention-deficit/hyperactivity disorder in adults with bipolar disorder or major depressive disorder: results from the international mood disorders collaborative project. Prim Care Companion J Clin Psychiatry. 2010. https://doi.org/10.4088/PCC.09m00861gry.

Merikangas KR, Akiskal HS, Angst J, Greenberg PE, Hirschfeld RM, Petukhova $M$, et al. Lifetime and 12-month prevalence of bipolar spectrum disorder in the National Comorbidity Survey replication. Arch Gen Psychiatry. 2007;64:543-52

Merikangas KR, Jin R, He J, et al. Prevalence and correlates of bipolar spectrum disorder in the world mental health survey initiative. Arch Gen Psychiatry. 2011;68:241-51.

Morriss R, Yang M, Chopra A, Bentall R, Paykel E, Scott J. Differential effects of depression and mania symptoms on social adjustment: prospective study in bipolar disorder. Bipolar Disord. 2013;15:80-91.

National Collaborating Centre for Mental Health. Bipolar disorder: the management of bipolar disorder in adults, children and adolescents, in primary and secondary care. CG185: NICE Guideline. National Institute for Health and Clinical Excellence. 2014.

Otto MW, Simon NM, Wisniewski SR, Miklowitz DJ, Kogan JN, Reilly-Harrington NA, et al. Prospective 12-month course of bipolar disorder in outpatients with and without comorbid anxiety disorders. Br J Psychiatry. 2006:189:20-5.

Perlis RH, Dennehy EB, Miklowitz DJ, DelBello MP, Ostacher M, Calabrese JR, et al. Retrospective age at onset of bipolar disorder and outcome during two-year follow-up: results from the STEP-BD study. Bipolar Disord. 2009;11:391-400

Pinheiro J, Bates D, DebRoy S, Sarkar D, R Core Team. nlme: linear and nonlinear mixed effects models. R package version 3.1-130. https://CRAN.R-proje ct.org/package =nlme. 2017.

Post RM, Nolen WA, Kupka RW, Denicoff KD, Leverich GS, Keck PE Jr, et al. The Stanley Foundation Bipolar Network. I. Rationale and methods. $\mathrm{Br}$ Psychiatry. 2001;178(S41):s169-76.

Post RM, Altshuler L, Leverich GS, Frye MA, Suppes T, McElroy SL, et al. Relationship of clinical course of illness variables to medical comorbidities in 900 adult outpatients with bipolar disorder. Compr Psychiatry. 2015;56:21-8.

Post RM, Leverich G, McElroy S, Kupka R, Suppes T, Altshuler L, et al. Prevalence of axis II comorbidities in bipolar disorder: relationship to mood state. Bipolar Disorder. 2018:20:303-12.

Provencher MD, Guimond AJ, Hawke LD. Comorbid anxiety in bipolar spectrum disorders: a neglected research and treatment issue? J Affect Disord. 2012;137:161-4.

Sandra Kooij JJ, Marije Boonstra A, Swinkels SH, Bekker EM, de Noord I, Buitelaar JK. Reliability, validity, and utility of instruments for self-report and informant report concerning symptoms of ADHD in adult patients. J Atten Disord. 2008;11:445-58.

Schoeyen HK, Birkenaes AB, Vaaler AE, Auestad BH, Malt UF, Andreassen OA, et al. Bipolar disorder patients have similar levels of education but lower socio-economic status than the general population. J Affect Disord. 2011;129:68-74.

Scott J, Scott EM, Hermens DF, Naismith SL, Guastella AJ, White D, et al. Functional impairment in adolescents and young adults with emerging mood disorders. Br J Psychiatry. 2014;205:362-8.

Sentissi O, Navarro JC, De Oliveira H, Gourion D, Bourdel MC, Bayle FJ, et al. Bipolar disorders and quality of life: the impact of attention deficit/hyperactivity disorder and substance abuse in euthymic patients. Psychiatry Res. 2008;161:36-42.

Simon NM, Otto MW, Wisniewski SR, Fossey M, Sagduyu K, Frank E, et al. Anxiety disorder comorbidity in bipolar disorder patients: data from the first 500 participants in the systematic treatment enhancement program for bipolar disorder (STEP-BD). Am J Psychiatry. 2004;161:2222-9.

Soderberg P, Tungstrom S, Armelius BA. Reliability of global assessment of functioning ratings made by clinical psychiatric staff. Psychiatr Serv. 2005;56:434-8

Vazquez GH, Baldessarini RJ, Tondo L. Co-occurrence of anxiety and bipolar disorders: clinical and therapeutic overview. Depress Anxiety. 2014:31:196-206

Vickers AJ, Altman DG. Analysing controlled trials with baseline and follow up measurements. BMJ. 2001:323:1123-4.

Wilens TE, Biederman J, Wozniak J, Gunawardene S, Wong J, Monuteaux M. Can adults with attention-deficit/hyperactivity disorder be distinguished from those with comorbid bipolar disorder? Findings from a sample of clinically referred adults. Biol Psychiatry. 2003;54:1-8.

Wingo AP, Ghaemi SN. Frequency of stimulant treatment and of stimulantassociated mania/hypomania in bipolar disorder patients. Psychopharmacol Bull. 2008:41:37-47.

\section{Publisher's Note}

Springer Nature remains neutral with regard to jurisdictional claims in published maps and institutional affiliations. 